14.3

\title{
Измерение температуры живых организмов при гипотермии
}

\author{
() К.Н. Большев, В.А. Иванов, А.С. Андреев \\ Институт фризико-технических проблем Севера им. В.П. Ларионова СОРАН, \\ 677980 Якутск, Россия \\ e-mail: k.bolshev@mail.ru
}

Поступило в Редакцию 14 апреля 2020 г.

В окончательной редакции 21 апреля 2020 г.

Принято к публикации 27 апреля 2020 г.

Представлены примеры исследований в области термометрии живых организмов, проведенные в Институте физико-технических проблем Севера СО РАН совместно с Центром изучения холодовой травмы при Якутском научном центре. Описан опыт измерения температуры пловцов-экстремалов при заплыве через Берингов пролив и полученные в результате данные, демонстрирующие экстремальное переохлаждение организма пловцов в процессе заплыва. Приведены результаты опытов по погружению собак в состояние глубокой гипотермии с непрерывной регистрацией температуры организма и клинических параметров.

Ключевые слова: температура, гипотермия, хладотравма, обморожение, переохлаждение, измерение и регистрация температур в организме.

DOI: $10.21883 /$ JTF.2020.10.49788.134-20

\section{Введение}

Переохлаждение организма, называемое в медицине гипотермией, является многогранным явлением. С одной стороны, это опасное для теплокровного организма состояние, чреватое травмами и прочими негативными последствиями вплоть до летального исхода. С другой стороны, контролируемая местная или общая гипотермия успешно применяется в современной медицине при лечении кровоизлияний, при черепно-мозговых травмах, операциях на сердце [1].

При общем переохлаждении нарушаются естественные процессы, замедляется обмен веществ, и организм может войти в состояние анабиоза. Это еще одно следствие гипотермии, которое вызывает интерес у исследователей во всем мире [2]. Проблема безопасного погружения живого организма в анабиоз и последующего полного оживления и восстановления всех его жизненных функций весьма актуальна и широко исследуема в настоящее время [3].

В условиях сурового климата Республики Саха (Якутия), когда зимой температура падает до $-60^{\circ} \mathrm{C}$, проблемы гипотермии и хладотравм имеют неоспоримую актуальность.

Минимизация последствий переохлаждения и обморожения и максимально возможное восстановление пострадавших органов и тканей - вот основной приоритет при лечении хладотравм. При этом большое значение имеет постоянный контроль температуры объекта. Измерение температуры травмированных тканей важно не только для мониторинга процесса лечения, но и для постановки точного диагноза и определения степени обморожения, в зависимости от чего выбирается способ оказания первой медицинской и врачебной помощи, являющийся решающим при выборе методов лечения и определяющим исход лечения [4]. Такой температур- ный контроль, называемый в медицине „термометрия“, подразумевает использование надежного и точного измерительного оборудования, а также наличие подготовленных и квалифицированных специалистов.

В настоящей работе приводятся примеры исследований и разработок в области термометрии, проведенные в Институте физико-технических проблем Севера СО РАН совместно с Центром изучения холодовой травмы при Якутском научном центре.

\section{1. Мониторинг температуры пловцов-экстремалов при заплыве через Берингов пролив}

Особый интерес при исследовании явления гипотермии представляют возможности специально тренирующихся спортсменов, привычных к экстремально холодным условиям.

В 1987 г. американка Лин Кокс установила рекорд, проведя в 6-градусной воде $2 \mathrm{~h} 6$ min и преодолев за это время $4160 \mathrm{~m}$ Берингова пролива [5].

Этот рекорд был побит нашими соотечественниками: в августе 2014 г. в Беринговом проливе состоялось уникальное событие - заплыв от острова Малый Диомид (США) до острова Ратманова (Россия) (рис. 1). Участники заплыва - пловцы-экстремалы Прокопчук Григорий (г.Якутск) и Брылин Александр (г.Благовещенск) проплыли почти $5.5 \mathrm{~km}$ в воде температурой от 3 до $6^{\circ} \mathrm{C}$ в течение $2 \mathrm{~h}$. На протяжении всего заплыва нами проводился мониторинг температуры тела пловцов.

В качестве основного инструмента были выбраны температурные логгеры iBDL DS1922L. Аббревиатура iBDL расшифровывается как iButton Data Loggers и обозначает семейство регистраторов (логгеров), серийно выпускаемых американской компанией Maxim Semiconductors. 
Они предназначены для мониторинга температуры и влажности.

Логгер iBDL представляет собой уникальный миниатюрный прибор, являющийся полностью автономным и защищенным одноканальным электронным самописцем в герметичном стальном корпусе MicroCAN весом $3.3 \mathrm{~g}$ и диаметром $17 \mathrm{~mm}$ (рис. 2).

Благодаря небольшим размерам один из датчиков легко можно поместить в желудок человека через пищевод. Второй датчик закреплялся на запястье с помощью обычного медицинского пластыря. Перед началом экспериментов датчики программируются оператором. Устанавливается частота и время старта опроса датчиков. В рассматриваемых наблюдениях датчики опрашивались с периодом $10 \mathrm{~min}$. Извлечение записанных в память показаний температуры происходит при помощи специального устройства, которое подключается к компьютеру при помощи разъема USB и передает данные на персональный компьютер.

Заплыв с острова Ратманова до острова Малый Диомид начался 1 августа 2014 г. приблизительно в $14 \mathrm{~h}$

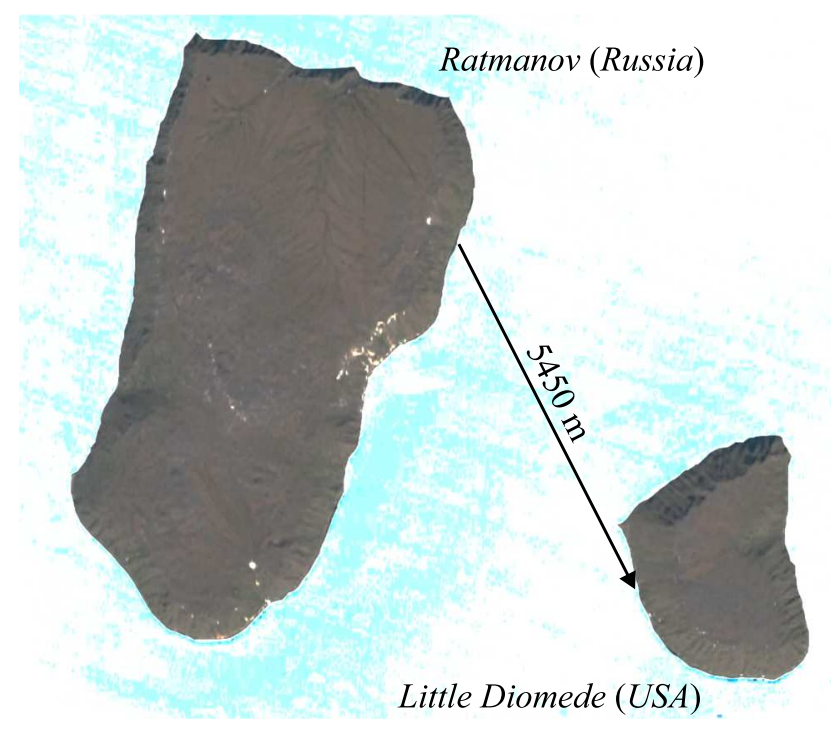

Рис. 1. Маршрут заплыва.

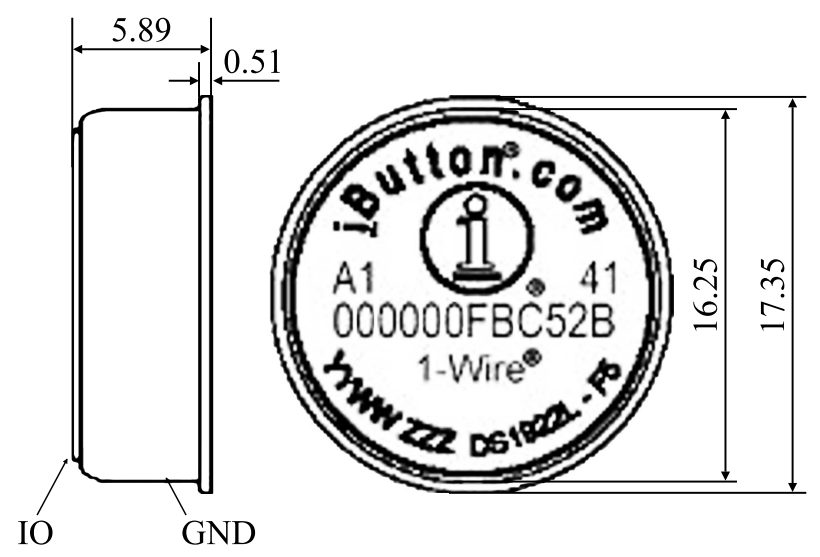

Pис. 2. Температурный логгер в корпусе MicroCAN.

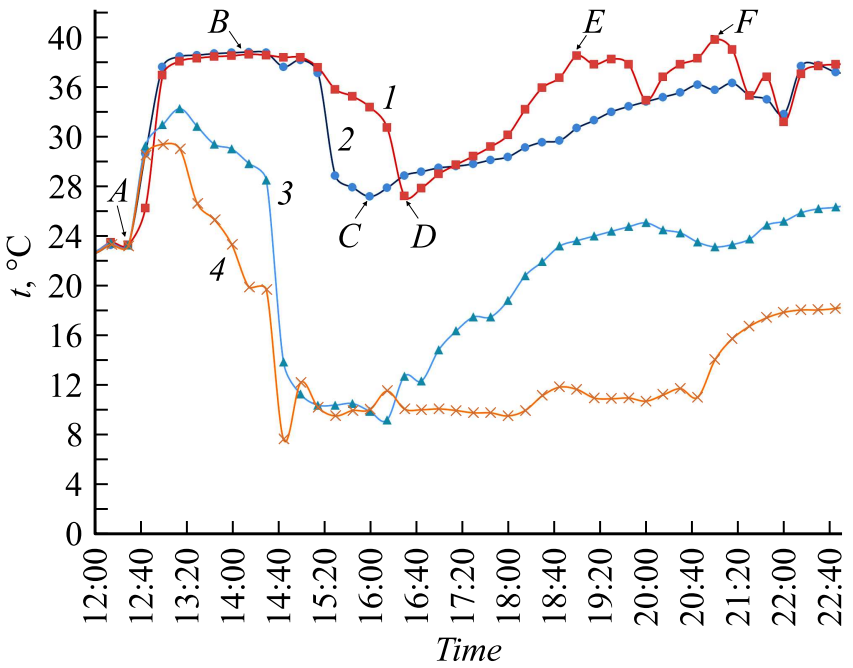

Рис. 3. Графики изменения температуры в течение заплыва: 1 - Брылин, желудок, 2 - Прокопчук, желудок, 3 - Брылин, рука, 4 - Прокопчук, рука. $A-$ размещение логгеров, $B$ - старт заплыва (14:23), $C$ - финиш Брылин (16:20), $D-$ финиш Прокопчук $(16: 40), E, F-$ принятие пищи и горячих напитков Прокопчуком.

$20 \mathrm{~min}$ и закончился примерно в $16 \mathrm{~h} 30 \mathrm{~min}$. Температура воды составляла от 3 до $6^{\circ} \mathrm{C}$. Пловцы преодолевали дистанцию разным стилем, Григорий плыл вольным стилем и провел в воде $1 \mathrm{~h} 57 \mathrm{~min}$, Александр плыл брассом и провел в воде $2 \mathrm{~h} 17 \mathrm{~min}$. Ход заплыва фиксировался на видеокамеру.

На момент старта пловцов логгеры в желудках зарегистрировали температуру около $39^{\circ} \mathrm{C}$. В процессе заплыва температура в желудке постепенно падала до значения около $27^{\circ} \mathrm{C}$ (рис. 3)!

После окончания заплыва восстановление нормального температурного режима организма длилось около $8 \mathrm{~h}$. Датчики, закрепленные на запястьях пловцов, в процессе заплыва фиксировали температуру около $10^{\circ} \mathrm{C}$.

Специалисты утверждают, что общее переохлаждение организма до таких температур $\left(20-28^{\circ} \mathrm{C}\right)$ считается тяжелой гипотермией и чревато опасностью остановки сердца. Учитывая то, что все это время спортсмены испытывали активную физическую нагрузку, можно сказать, что нами были зафиксированы уникальные возможности подготовленного и тренированного человеческого организма.

\section{2. Термометрия и изменение общих клинических параметров и показателей сердечно-сосудистой системы при гипотермии собак}

Явление анабиоза широко распространено в живой природе. Под анабиозом обычно понимают такое состояние организма, при котором жизненные процессы настолько замедляются, что отсутствуют все проявления 


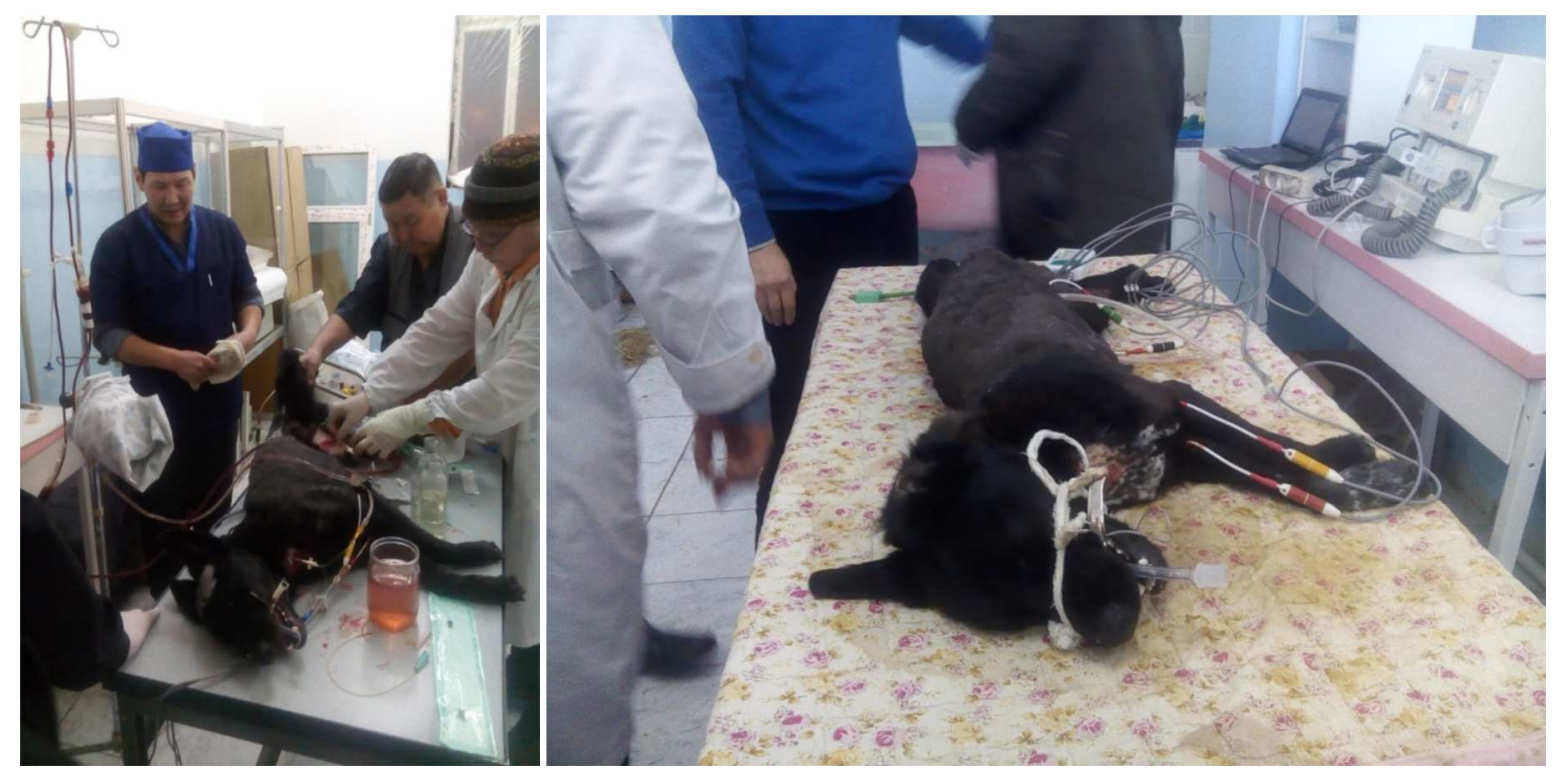

Pис. 4. Эксперименты по погружению собаки в состояние глубокой гипотермии.
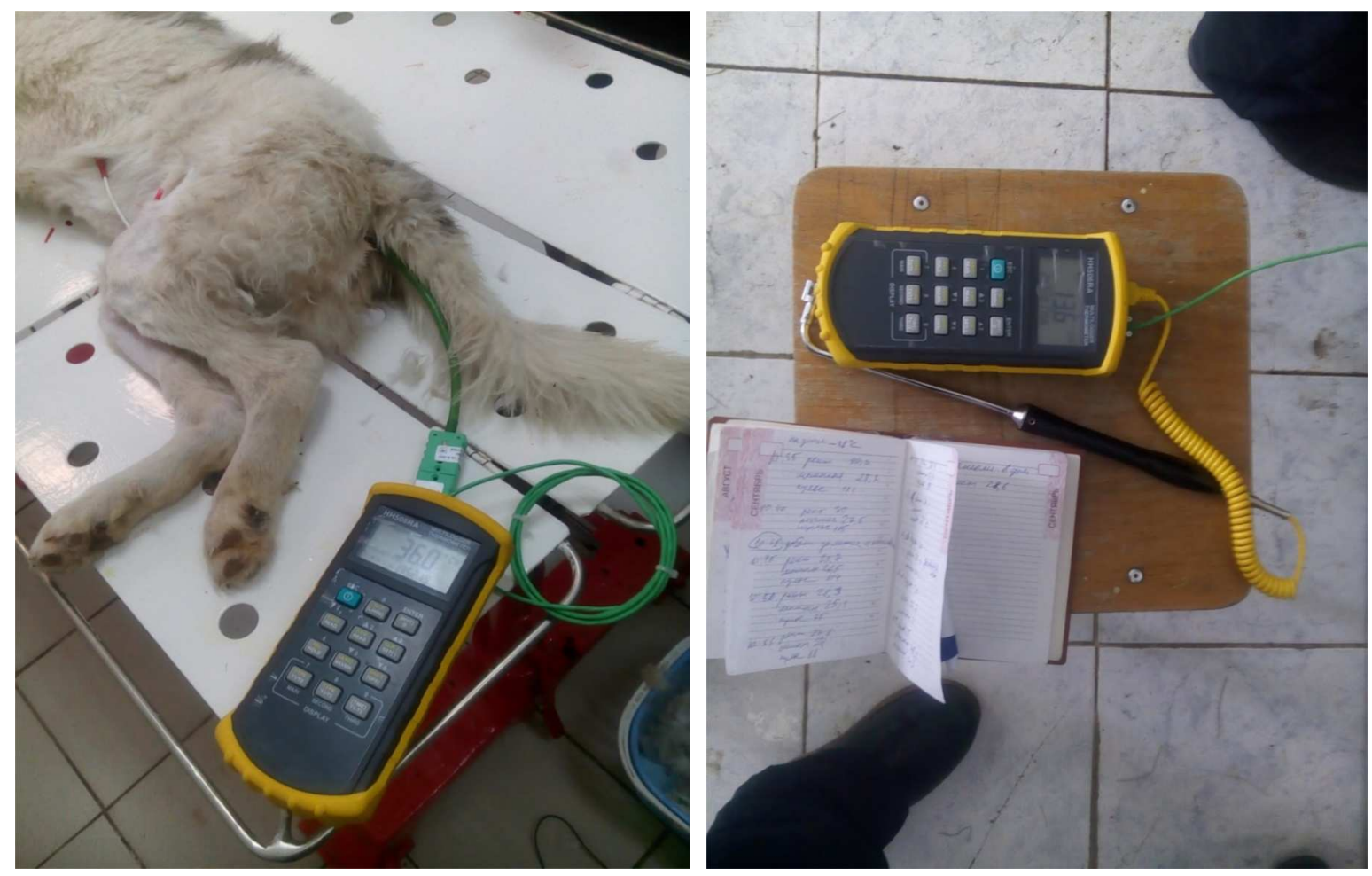

Рис. 5. Двухканальный измеритель температуры HH506RA.

жизни, при наступлении благоприятных условий нормальная интенсивность жизненных процессов восстанавливается. Большой вклад в развитие представлений об анабиозе внес русский физик и биолог-экспериментатор П.И. Бахметьев [6]. В начале ХХ в. он, исследуя явление зимней спячки у животных в естественных условиях, обнаружил, что в организме у этих животных происходит резкое снижение жизнедеятельности всех органов.
Изучение глубокой гипотермии у млекопитающих начиналось с работ, проведенных главным образом на мелких животных (сурки, суслики, хомяки, крысы). Полученные данные позволили убедиться в возможности искусственного снижения температуры тела до $0-5^{\circ} \mathrm{C}$ и даже ниже нуля, а затем, через $1-2 \mathrm{~h}$, путем разогрева восстановления всех жизненных функций организма. Изучению глубокой гипотермии у мелких млекопита- 
ющих в Республике Саха (Якутия) посвящены работы Ахременко А.К. и Ануфриева А.И. [7-11].

Известно, что гипотермическое состояние организма оказывает нейропротекторное действие при различных гипоксических патологиях. Протективные свойства гипотермии исследовали корифеи отечественной реаниматологии Неговский В.А., Трещинский А.И. и Чепкий Л.П. Исследования в области методов погружения в гипотермию и анабиоз Самуэля Тишермана и Питера Ри [12] демонстрируют возможность сохранения организма в критическом состоянии с использованием анабиоза и последующую возможность реанимации.

Для исследования процессов в живом организме в состоянии гипотермии, а также наработки методик оживления организма при гипотермии, на базе факультета ветеринарной медицины Якутской государственной сельскохозяйственной академии проводились экспериментальные работы по переохлаждению организма живой собаки.

Данные экспериментальные исследования были выполнены с соблюдением применимых норм. В качестве объектов исследования выбирались животные из местного питомника, определенные к усыплению. Для проведения опытов было получено соответствующее разрешение биоэтической комиссии.

Эксперимент заключался в погружении объекта в состояние глубокой гипотермии при температуре среды $-40^{\circ} \mathrm{C}$, и, как следствие, клинической смерти, при применении различных препаратов, с постоянным контролем клинических параметров и непрерывной термометрии, с последующей попыткой оживления (рис. 4).

В целях общей анестезии применялись препараты нейролептаналгезии (нейролептик - Рометар $0.2 \%$ и анальгетик - Золетил 100). Общеклинические параметры исследовали общепринятыми методами. Температуру ядра собаки регистрировали с помощью температурного логгера $\mathrm{iBDL}$. Отдельно регистрировали ректальную

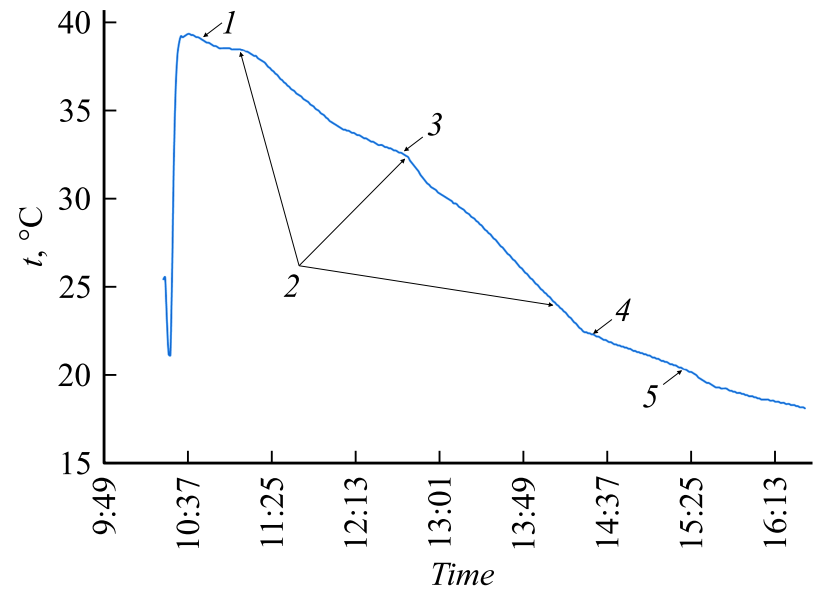

Рис. 6. Изменение температуры в желудке в течение эксперимента: 1 - пероральное помещение логгера в желудок, 2 - применение препаратов Ксиловет и Золетил, 3 - помещение собаки в холод, $4-$ клиническая смерь, 5 - начало реанимационных действий.

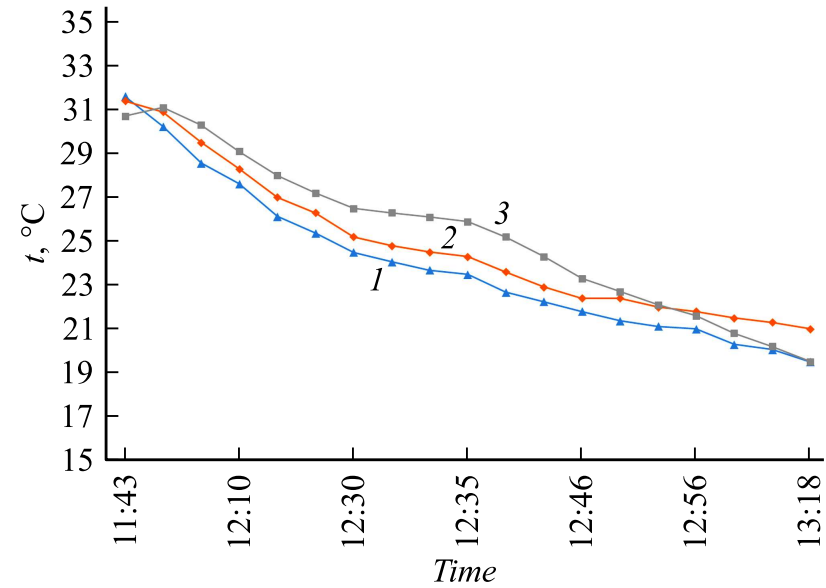

Рис. 7. Сопоставленный график ректальной и внутрижелудочной температуры в период гипотермии $\left(-35^{\circ} \mathrm{C}\right): 1-$ температура в желудке, 2 - ректальная температура, 3 - мышечная температура.

и мышечную температуру двухканальным измерителем температуры HH506RA (рис. 5) по методике Алексеева Р.3. [13]. ЭКГ проводили с помощью аппарата Полиспектр 8/В. Для предотвращения свертывания крови вводили антикоагулянт гепарин.

В процессе опытов были использованы различные методики реанимации. В первом случае использовался механизм разогрева организма теплой водой через ПВХтрубки интраперитониально, прямой и непрямой массаж сердца, введение адреналина, искусственное дыхание. Во втором случае использовались перфузия крови аппаратом гемодиализа крови с использованием дефибриллятора, артериальное нагнетание подогретой крови с температурой $37^{\circ} \mathrm{C}$ в правую бедренную артерию и через правую бедренную вену обратно в аппарат, введение адреналина, искусственное дыхание.

К сожалению реанимационные методы не дали положительного результата.

На рис. 6 и 7 представлены результаты термометрии в процессе одного из экспериментов. В результате проведенных опытов можно установить, что закономерность снижения температур ректальной и мышечной зависят от температуры окружающей среды. При воздействии низких температур происходило постепенное замедление атриовентрикулярного проведения и соответственное замедление ритма сердца брадикардия. Механизм гипотермии животных отличается от человеческого. Ректальная температура снижается медленнее, чем желудочная, так как процесс снижения общей температуры у собаки происходит за счет дыхания, а у человека за счет охлаждения конечностей и головы.

\section{Выводы}

Опыты с животными дали возможность установить ряд факторов, затрудняющих процесс восстановления 
жизненных функций организма. К ним относятся длительное охлаждение животных и несовершенный наркоз, приводящие к более частому развитию фибрилляции желудочков; острое расширение сердца, поддерживающее вялую, трудно устранимую фибрилляцию желудочков, сложность механизма восстановления работы головного мозга при выводе из гипотермии. Все перечисленные проблемы требуют дополнительных технических решений.

Экспериментальные исследования по данной проблеме „оживления“ будут продолжены. Идея возможности оживления организма после холодового сна развивается и, несомненно, будет играть немалую роль в борьбе за жизнь и здоровье человека.

\section{Соблюдение этических стандартов}

Все применимые международные, национальные и/или институциональные принципы ухода и использования животных были соблюдены.

\section{Конфликт интересов}

Авторы заявляют, что у них нет конфликта интересов.

\section{Список литературы}

[1] Неговский B.A. Глубокая гипотермия как способ удлинения сроков клинической смерти / В.А. Неговский, В.И. Соболева, Н.Л. Гурвич, К.С. Киселева. Бюллетень экспериментальной биологии и медицины. 1963. Т. 56. № 11. C. 39-43.

[2] Анубриев А.И. // Наука и образование. 2015. № 1. С. 109 118.

[3] Ахременко А.К., Анубриев А.И., Соломонов Н.Г., Соломонова Т.Н., Васильев В.Н. // Сибирский экологический журнал. 1998. № 3-4. С. 34-352.

[4] Справочник врача скорой и неотложной медицинской помощи / Под ред. проф. М.В. Гринева и д-ра мед. наук И.Н. Ершовой. СПб.: Политехника, 2000.

[5] Cox L. Swimming in the Sink. A memoir Vintage Books, 2017.

[6] Бахметьев П.И. // Природа. 1912. 1. № 12. С. 1441.

[7] Ахременко А.К. Эколого-физиологическая характеристика якутского суслика. Автореф. канд. дис. Свердловск, 1981. $17 \mathrm{c}$.

[8] Ахременко А.К., Ахременко Я.А , Пшенникова Е.В. // Якутский медицинский журнал. 2018. № 2. С. 17-20.

[9] Ануфриев А.И., Ядрихинский В.Ф. // Принципы экологии. 2019. № 3. C. 12-23.

[10] Анубриев А.И., Соломонова Т.Н., Круман И.И. Наблюдения за зимней спячкой якутского длиннохвостого суслика в условиях эксперимента. Адаптация животных к холоду. Новосибирск: Наука, 1990. С. 21-27.

[11] Анубриев А.И. Экологические механизмы температурных адаптаций млекопитающих и зимующих птиц Якутии. Новосибирск: Изд-во СО РАН, 2013.

[12] Tisherman S.A., Alam H.B., Rhee P.M. // J. Trauma Acute Care Surgery. 2017. Vol. 83. N 5. P. 803-809.

[13] Алексеев P.3. Врачебная помощь при отморожениях в дореактивном периоде и общем охлаждении организма. Информационное письмо. 2004. 